\section{STAPLER VERSUS PRECISION DISSECTION AND SEALANT IN COMPARING COMPLETION TECHNIQUE OF FISSURES FOR LOBECTOMY: TRUE OR STATISTICAL ADVANTAGES?}

\section{To the Editor:}

We read with interest the article by Droghetti and colleagues ${ }^{1}$ and congratulate the authors. Although we agree that sealants are a step forward in the control of air leaks after lung resection, there are some points that should be clarified. In the introduction, the authors state that surgical staplers provide reliable hemostasis without obtaining an airtight closure of parenchymal tears; in support of this they quote a 24 -year-old article, ${ }^{2}$ but staplers have changed since that time and they do not give details about the kind of stapler they used. Also, details should be given on the surgical technique: In a grade 3 and mainly a grade 4 Craig's fissure classification, ${ }^{3}$ do the authors use a retrograde dissection?

The chest tubes were in place for a mean of 7.6 days in the electrocautery/sealant group and 10.2 days in the stapler group; however, a patient in the stapler group had a chest tube in place for 55 days and was discharged after 57 days (the reason is not specified; maybe this is the patient who had a chylothorax). Mean can be misleading, and it is influenced by the extreme values; means are usually reported with standard deviation and

\footnotetext{
The Editor welcomes submissions for possible publication in the Letters to the Editor section that consist of commentary on an article published in the Journal or other relevant issues. Authors should: • Include no more than 500 words of text, three authors, and five references. - Type with double-spacing. - See http://jtcs.ctsnetjournals.org/misc/ifora.shtml for detailed submission instructions. - Submit the letter electronically via jtcvs.editorialmanager.com. Letters commenting on an article published in the JTCVS will be considered if they are received within 6 weeks of the time the article was published. Authors of the article being commented on will be given an opportunity of offer a timely response ( 2 weeks) to the letter. Authors of letters will be notified that the letter has been received. Unpublished letters cannot be returned.
}

not with the range as in the authors' article. To have more reliable data, the authors should have better reported medians rather than means or removed the patient who had the chest drain in place for a long time. By doing so, the length of chest tube in place, the length of hospitalization, and the cost of hospitalization would have been similar in both groups of patients. Last, in the "Discussion" the authors state that all parameters of air leakage were statistically significant with lower values for the experimental group, but it does not seem to be of clinical significance.

Alberto Terzi, MD

Paolo Scanagatta, $M D$

Giovanna Rizzardi, MD

Thoracic Surgery Unit

Azienda Ospedaliera S.Croce e Carle Cuneo, Italy

\section{References}

1. Droghetti A, Schiavini A, Muriana P, Folloni A, Picarone M, Bonadiman C, et al. A prospective randomized trial comparing completion technique of fissures for lobectomy: stapler versus precision dissection and sealant. J Thorac Cardiovasc Surg. 2008;136:383-91. Epub 2008 Jun 16.

2. Hood RM. Stapling techniques involving lung parenchyma. Surg Clin North Am. 1984;64:469-80.

3. Craig SR, Walker WS. A proposed anatomical classification of the pulmonary fissure. $J R$ Coll Surg Edinb. 1997;42:233-4.

$$
\text { doi:10.1016/j.jtcvs.2008.09.077 }
$$

\section{Reply to the Editor:}

We thank Terzi et al for their founded observations on our pilot study, thus giving us the opportunity to elaborate on and reinforce some aspects of our article.

There is much literature dealing with monitoring of intraoperative and postoperative air leaks after lung resection. The incidence of intraoperative air leaks in the various series ranges from $50 \%$ to $80 \%$, whereas the incidence of postoperative air leaks within 48 hours of surgical intervention oscillates around $30 \% .{ }^{1,2}$

The surgical staplers used in the Stapler (ST) group were the classic linear GIA (single-use loading units with tita- nium staples), which can be found commercially.

The incidence of intraoperative air leaks was slightly higher than in the literature, and this is obviously due to the fact that only patients presenting with fissures classified as grade 3 and 4 by using Craig's scale were included in the study, resulting in an increased area of parenchymal dissection. The incidence of air leakage in the first 48 hours was in line with other studies.

The surgical technique that is normally used in patients with fissures with substantial or complete fusion (Craig's scale 3 and 4) is that described as the "fissureless technique" by various authors, meaning that the bronchus is closed and sectioned before dividing the pulmonary parenchyma. ${ }^{3}$

With regard to postoperative aspects, our research evidenced more clinical benefits than statistically significant findings because of the reduced population of our trial group. The considerably shorter duration of air leaks observed in the electrocautery and sealant (ES) group (mean, 1.7 vs 4.5; median, 0.5 vs $3 ; P=0.003$ ) did not result in a statistically significant reduction of chest tube permanence or length of hospitalization, although both were considerably shortened. Persistent air leakage ( $>7$ days) was present in $15 \%$ of patients in the ST group versus only $5 \%$ of patients in the ES group. Dead pleural space was present in $40 \%$ of patients in the ST group and only $5 \%$ of patients in the ES group.

We believe that all of these aspects demonstrate the clinical advantages of precision dissection and sealant versus the standard procedure with staplers, laying a solid foundation for further studies on their significance using a multicentric trial with greater statistical power.

Andrea Droghetti, $M D$

Andrea Schiavini, $M D$

Giovanni Muriana, MD

Thoracic Surgery Division

Carlo Poma Hospital Mantova, Italy 


\section{References}

1. Lang G, Csekeö A, Stamatis G, Lampl L, Hagman L, Marta GM, et al. Efficacy and safety of topical application of human fibrinogen/thrombin-coated collagen patch (TachoComb) for treat- ment of air leakage after standard lobectomy. Eur J Cardiothorac Surg. 2004;25:160-6.

2. Wain JC, Kaiser LR, Johnstone DW, Yang SC, Wright CD, Friedberg JS, et al. Trial of a novel synthetic sealant in preventing air leaks after lung resection. Ann Thorac Surg. 2001;71:1623-9.
3. Nomori H, Ohtsuka T, Horio H, Naruke T, Suemasu K. Thoracoscopic lobectomy for lung cancer with a largely fused fissure. Chest. 2003;123: 619-22.

doi:10.1016/j.jtcvs.2008.11.009 